\title{
Perspectivas do avatar: espírito de seriedade e má-fé
}

\author{
Marta M. Kania \\ Doutora; University of Lower Silesia, Wrocław, Polônia \\ martamatyldakania@gmail.com \\ Tradução: Mariana Amaro \\ Universidade Federal do Rio Grande do Sul, Porto Alegre, RS, Brasil \\ mari.amaroc@gmail.com \\ Revisão de tradução: Natan Fritscher Kussler \\ Universidade Federal do Rio Grande do Sul, Porto Alegre, RS, Brasil \\ natan.kussler@ufrgs.br
}

\section{Resumo}

Este ensaio teórico explora a experiência e o posicionamento de jogadores dentro do mundo do jogo a partir de uma perspectiva interna, buscando compreender as condições de uma situação de gameplay como um "eu-avatar". Analisa aspectos do mundo, jogador e avatar do game The Vanishing of Ethan Carter a fim de ilustrar e dar suporte aos seus argumentos teóricos sobre o processo de produção de significados em relação ao posicionamento interno do eu-avatar no jogo. Contextualiza conceitos existencialistas relacionados à situação de vida desenvolvidos por Jean-Paul Sartre, como má-fé e espírito de seriedade, à situação de gameplay, ao refletir teoricamente sobre a relação entre ser, jogador e avatar no jogo através da interseção da Filosofia e dos Estudos de Jogos. Propõe que a produção de significado e a interpretação da experiência individual dos jogadores ocorrem na interconexão entre múltiplas perspectivas, proporcionadas pela complexidade do posicionamento do jogador em relação ao jogo, ao avatar e ao mundo do jogo. Defende que a perspectiva do jogador e o posicionamento no jogo não podem ser experimentados separadamente do avatar, já que o eu-avatar é um ser emergente situado dentro do mundo do jogo que consiste tanto na existência e nos atos intencionais do jogador, assim como nas características do avatar.

\section{Palavras-chave}

Avatar. Mundo de jogo. Gameplay. Produção de Significado. The Vanishing of Ethan Carter. 
Talvez não possa ser de outro modo; talvez seja preciso escolher: não ser nada ou representar o que se é. Mas é terrível, essa trapaça da nossa própria natureza. (SARTRE, 1963, p. 184)12.

\section{Introdução}

Uma situação de gameplay ocorre quando o jogo é percebido como um mundo significativo e autônomo no qual a jogadora está situada ${ }^{3}$, e é colocado em oposição ao ponto de vista externo ao mundo do jogo no qual se considera que o jogo é um artefato. Portanto, o processo de produção de significado e a experiência de significância - os quais são os interesses primários do presente capítulo - estão fundamentados no ponto de vista interno ao mundo do jogo. A perspectiva perceptual da jogadora dentro deste mundo é definida por um avatar experimentado como eu-mesmo, ou seja, o eu-avatar, e sua posição dentro do mundo do jogo. A situação de gameplay inclui a realização do projeto existencial do euavatar, que age dentro do mundo do jogo e está sujeito a restrições internas do jogo. A partir dessa perspectiva, as atividades da jogadora motivadas pelos eventos que ela encontra no mundo do jogo são percebidas como significativas por meio de sua relação com: a) o mundo do jogo ou b) a atitude do eu-avatar em relação a elas. Portanto, a situação do gameplay é, em muitos aspectos, análoga à uma situação de vida. Esta última é um sistema de relações entre um indivíduo, um mundo e a facticidade; isto é, de acordo com Sartre (1997), a posição do indivíduo no mundo determina seu ponto de vista.

Nas próximas páginas, eu argumento que o significado das atividades dentro do jogo está enraizado na má-fé (SARTRE, 1997; LEINO, 2012a) e no espírito de seriedade (SARTRE, 1997). Jean-Paul Sartre usa esses termos em O Ser e O Nada (SARTRE, 1997) ${ }^{4}$ para nomear duas estratégias diferentes de defesa usadas pelos indivíduos para aliviar a tensão da responsabilidade. Elas são descritas por Sartre como crenças enganosas e prejudiciais sobre

\footnotetext{
${ }^{1}$ Nota do tradutor: A autora deste artigo utilizou uma versão em polonês de "Os Caminhos da Liberdade - Com a morte na alma" de Jean-Paul Sartre como referência, optando por traduzir ela mesma, do polonês para o inglês, as citações diretas a obra de Sartre. Por isso, a fim de não retraduzirmos ainda mais uma vez os trechos dessa obra - publicada originalmente em francês -, e aumentarmos ainda mais o ruído entre o original e a tradução, optamos aqui por buscar, referenciar e citar os trechos equivalentes em uma versão publicada em português desse livro, enquanto indicamos a versão utilizada pela autora no rodapé. Essa postura também foi adotada nas demais citações referentes a obras que já tenham sido publicadas na língua portuguesa.

2 Nota do tradutor: 0 artigo original utilizou a seguinte versão: SARTRE, Jean-Paul. Drogi wolności. Translated by Julian Rogoziński. Kraków: Zielona Sowa, 2005.

${ }^{3}$ Portanto, em uma situação de gameplay o jogador não se relaciona com o jogo como um artefato ou como um texto que pode ser lido erroneamente, livremente interpretado ou comparado a outros jogos.

4 Nota do tradutor: 0 artigo original utilizou a seguinte versão: SARTRE, Jean-Paul. Being and Nothingness: A Phenomenological Essay on Ontology. Translated by Hazel E. Barnes. New York: Pocket Books, 1978.
} 
a posição dos indivíduos no mundo e sobre a fonte do significado de suas ações. Má-fé é uma forma de autoengano intencional que faz a pessoa acreditar que seu papel no mundo é determinado; no entanto, elas não são capazes de esquecer completamente sua natureza projetiva. Por outro lado, o espírito de seriedade é uma convicção de que o significado do mundo não é dependente de um projeto individual, mas está inscrito em objetos. Portanto, numa situação de vida, o espírito de seriedade e a má-fé escondem o fato de que os seres humanos são livres e totalmente responsáveis por seus projetos existenciais. No entanto, quando introduzido na análise de jogos, eu argumento que eles descrevem um enquadramento perceptivo fornecido por um eu-avatar em experimentação de um mundo de jogo. Em consequência, ao invés de serem as características de uma luta moralmente falha com a liberdade individual, elas se tornam uma parte da forma estética do ser-nomundo-de-jogo abordado na situação estética.

0 argumento é acompanhado por uma interpretação de momentos específicos de The Vanishing of Ethan Carter (que daqui em frente será referenciado como VoEC) que serão entrelaçados mais adiante no texto, após a exposição teórica do problema. A situação do gameplay é aqui delineada pelo mundo do jogo, onde o eu-avatar é um detetive com poderes sobrenaturais que tenta resolver o mistério de um menino desaparecido, Ethan. 0 detetive considera significativas as ações que o levam a esse objetivo porque ele foi chamado para decifrar mensagens e pistas escondidas no mundo do jogo.

Como, então, o processo de construção de significado e a experiência de significância mudam em uma situação de gameplay, quando comparados à uma situação de vida? Para responder a essas perguntas, comparo o significado de má-fé e de espírito de seriedade nas situações de vida e nas de um jogo. Em primeiro lugar, preciso demarcar uma condição e as características da posição de um indivíduo no mundo dentro da estrutura da filosofia Sartriana. Vou destacar como o significado é criado em uma situação de vida e como isso depende do projeto existencial geral do indivíduo e de sua atitude em relação ao mundo. Consequentemente, eu aplicarei os pressupostos subjacentes da ontologia de Sartre a uma situação de gameplay, a fim de explorar como esse significado depende da posição de um euavatar e de sua atitude em relação ao mundo de jogo. 


\section{Seres humanos livres em um mundo absurdo}

$\mathrm{O}$ que o processo de produção de significado implica para os seres humanos? $\mathrm{Na}$ filosofia existencial de Sartre, o mundo não tem significado, portanto, o mundo não é capaz de fornecer os significados que o indivíduo dá à sua vida. Não só ele é completamente livre para iniciar o processo de produção de significado, mas também é completamente responsável por quem ele é e como ele age. Sartre apresenta um extremismo orientado à liberdade, afirmando que o sentido da vida é uma questão de escolha do indivíduo: "todas essas pequenas esperas passivas pelo real, todos esses valores banais e cotidianos tiram seu sentido, na verdade, de um projeto inicial meu, espécie de eleição que faço de mim mesmo no mundo" (SARTRE, 1997, p. 83-84), ele escreve. É uma questão do projeto existencial particular, pelo qual toda produção de significado do indivíduo é fundamentada na liberdade.

A compreensão Sartriana da liberdade está longe do uso cotidiano do termo. Aqui, liberdade não é entendida como possibilidade de escolha entre as opções apresentadas. Por exemplo, eu decido me tornar atriz, mergulhadora ou filósofa. A liberdade é entendida como "relação com o dado" (SARTRE, 1997, p. 599), ou seja, como uma possibilidade de negação a liberdade Sartriana constitui as características fundamentais do ser humano no mundo. Essa absolutização da liberdade torna cada decisão e ação uma consequência de decisão consciente pela qual deve-se assumir a responsabilidade. Isso também justifica a afirmação Sartriana de que o ser humano é nada e não pode deixar de ser livre (SARTRE, 1997).

Portanto, um ser humano pode não ter essência, mas tem a experiência de anseio interminável por algo que ele foi no passado ou quer se tornar. Enquanto um indivíduo, ele é nada; um vazio em ser que, devido à sua outridade, é capaz de interagir livremente com o mundo; o mundo é indiferente à plenitude e ao ser. Portanto, não é possível responder à pergunta "qual é o significado de uma árvore" sem se referir ao indivíduo humano. A árvore em particular pode ser considerada como uma fonte de inspiração ou como lenha - seu significado depende do projeto que alguém conecta à árvore. É, portanto, a liberdade que constitui significado do mundo: intenções, ações e suas interpretações.

No entanto, os seres humanos sempre se encontram dentro de um mundo indiferente como se fossem jogados (SARTRE, 1997) em uma situação particular que eles estão encarando a partir de um ponto de vista particular. Sartre acrescenta que: 
[...] o para-si se encontra em presença de sentidos que não vêm ao mundo por ele. 0 para-si surge em um mundo que a ele se mostra como já visto, cultivado, explorado, trabalhado em todos os sentidos e cuja contextura mesmo já está definida por essas investigações. (SARTRE, 1997, p. 638).

Esse envolvimento da consciência é a facticidade:

\begin{abstract}
Sem a facticidade, a consciência poderia escolher suas vinculações com o mundo, da mesma forma como, na República de Platão, as almas escolhem sua condição: eu poderia me determinar a "nascer operário" ou "nascer burguês". Mas, por outro lado, a facticidade não pode me constituir como sendo burguês ou sendo operário. Ela sequer é, propriamente falando, uma resistência do fato [...]. A facticidade é apenas uma indicação que dou a mim mesmo do ser que devo alcançar para ser o que sou. (SARTRE, 1997, p. 133)
\end{abstract}

Ao estabelecer a relação de um indivíduo com o mundo, a facticidade não retira o fardo da liberdade. Mesmo que uma atividade convencional seja experimentada como motivada ou imposta pelas exigências de uma situação particular, ela precisa ser livremente escolhida pelo indivíduo como o seu próprio modo de agir. Portanto, qualquer ato se torna justificado por si mesmo; o ato não se torna melhor, pior, inocente ou sem sentido. Além disso, o indivíduo não pode deixar de assumir total responsabilidade por esse ato.

Para Sartre, uma compreensão do nada incondicional e da inescapável liberdade próprios do indivíduo é, então, a única fonte de sentido de significado profundo e autêntico. Além disso, estar ciente dessa liberdade causa angústia, pois ninguém e nada é dado como apenas significativo (SARTRE, 1997). O existencialismo Sartriano é a filosofia da liberdade difícil, uma vez que considera um indivíduo como absolutamente responsável (ver, por exemplo, SARTRE, 1997; DILMAN, 2013). Em consequência, como ele escreve em Os Caminhos da Liberdade - com a morte na alma, "todos, todos tiravam o corpo: Schwartz transformava-se. Nippert agarrava-se ao sono. Pinette à cólera. [...]. Cada um dêles apressadamente constituíra a atitude que lhe permitia viver". (SARTRE, 1968, p. 72). Todos esses significados "dados pela vida" derivam da má-fé; se acredita neles devido ao seu efeito tranquilizante. A dificuldade de assumir a responsabilidade pela liberdade é a razão de uma presença comum dos mecanismos de defesa da má-fé e do espírito de seriedade. Eles escondem a liberdade e a angústia, e ajudam os indivíduos a perceber suas ações - assim como o mundo ao seu redor - como justificados e significativos (SARTRE, 1997).

Sartre argumenta que "para o espírito de seriedade, de fato, o pão é desejável, por exemplo, porque é necessário viver (valor inscrito no céu inteligível) e porque é nutritivo" (SARTRE, 1997, p. 763). Eu acho que uma pista para essa atitude pode ser exemplificada por 
duas formas de sentenças. Um ser humano, em espírito de seriedade, expressará suas experiências pelas características dos objetos e dirá: "isto é compreensível, comestível, perceptível"; enquanto o consciente de sua liberdade articulará sua atitude em relação ao mundo na forma ativa, "eu posso entender, comer, perceber". Enquanto um indivíduo sério objetiva significados e valores, ele acredita que tudo exige um tratamento particular e deve ser abordado apenas do modo "apropriado" que sirva à sua natureza.

A má-fé, por sua vez, é uma resposta para o desejo de ser determinado e limitado a um papel desempenhado. É uma resposta falsa, mas convincente, que o indivíduo se dá por desejar um lugar apropriado e imutável no mundo. A má-fé é uma forma especial de autoengano quando uma pessoa desempenha um papel que conhece, reconhece ou considera ser a sua natureza real e, ao mesmo tempo, tenta esconder a sua própria convicção de que é apenas uma das relações possíveis oferecidas. “É da minha natureza, eu sempre faço isso", ou "eu adoraria te ajudar, mas transgride minha elegibilidade" são dois exemplos de enunciados formulados do ponto de vista da má-fé5.

As duas estratégias, má-fé e espírito de seriedade, serão explicadas de forma mais compreensível através de exemplos do jogo The Vanishing of Ethan Carter.

\section{Não há lugar para o absurdo no espírito da seriedade}

Minha liberdade? Ela me pesa. Há anos que sou livre à toa. Morro de vontade de trocá-la por uma convicção. De bom grado trabalharia com vocês, isso me afastaria de mim mesmo e tenho necessidade de me esquecer um pouco. (SARTRE, 1963, p. 130)

Será que os mecanismos de defesa da má-fé e espírito de seriedade funcionam em uma situação de gameplay da mesma forma do que em uma situação de vida? E se eles realmente funcionam, como eles estão manifestados? Com base na ontologia Sartriana da condição humana, eu tentarei delinear a situação do eu-avatar nos mundos de jogos do gênero de aventura, caracterizado pela ausência da condição de perder nesse gênero de jogo. Em outras palavras, a experiência dos jogadores com esse tipo de jogo pode ser mais ou menos extensa devido à suas atividades dentro do mundo do jogo, mas não há possibilidade de eles falharem.

\footnotetext{
${ }^{5} \mathrm{O}$ termo má-fé já foi aplicado aos jogos por Olli T. Leino. Isso será discutido mais adiante no texto.
} 
Eu gostaria de limitar a aplicação da ontologia Sartriana a esse gênero, pois o estreitamento do campo irá me permitir explorá-lo com mais cuidado. Consequentemente, vou focar no $V o E C$, o jogo de aventura com uma "posição-de-sujeito lúdico incorporado singularmente [...] onde a jogadora recebe uma única figura jogável, sendo que sua relação com o mundo do jogo é inteiramente estruturada por seu engajamento com essa figura" (VELLA, 2016, p. 5). 0 mundo de jogo é percebido de uma perspectiva de primeira pessoa e como um ambiente tridimensional. Em primeiro lugar, gostaria de destacar as diferenças entre o mundo Sartriano - no qual os seres humanos são lançados - e o mundo de jogo - no qual os seres humanos se lançam voluntariamente.

O jogo, antes que eu o execute, é para mim um artefato ou um objeto no mundo (AARSETH, 2011; LEINO, 2010). Eu sou livre em relação a ele: eu posso ligá-lo e entrar em uma situação de gameplay ou optar por não fazê-lo. Quando tomo uma decisão e entro na situação do jogo, sinto que começa uma aventura: a aventura tão desejada por Roquentin, protagonista de A Náusea (SARTRE, 2007) ${ }^{6}$. Segundo Sartre, uma aventura é "um modo de acontecimento", onde "vida" e "história", "viver" e "relatar" estão interligados (SARTRE, 2007). Ao ter uma aventura, uma pessoa experimenta sua vida como se ela fosse a protagonista de uma história fascinante. Ela participa dos eventos, mas não é a criadora deles - tudo se encaixa, mas ações não causam a aventura, nem determinam seu curso.

Sartre escreve que o anseio por uma aventura nunca pode ser totalmente satisfeito na vida, pois o mundo não tem sentido; é absurdo e excessivamente complicado. Entretanto, uma vez que os mundos dos jogos em discussão não compartilham com a realidade a qualidade de "um excesso em si mesma" (SARTRE, 2000, p. 193) isto é, oferecer mais possibilidades do que as que podem ser experimentadas; eles são potencialmente reconciliáveis com a consciência humana. Além disso, os mundos de jogos de aventura geralmente oferecem os papéis centrais aos eu-avatares.

Portanto, apesar do lugar em que me encontro quando começo em VoEC parecer bastante realista, eu espero que o momento seja o início real que nunca poderá acontecer na vida - já que "verdadeiros começos surgindo como um toque de clarim, como as primeiras notas de uma melodia de jazz, bruscamente, cortando o tédio, fortalecendo a duração"; (SARTRE, 2000 p. 63). Quando o eu-avatar dá a volta, ele percebe uma entrada para o túnel. Levado pela curiosidade, ele corre para dentro - o que ele encontrará no lado oposto do

\footnotetext{
${ }^{6}$ Nota do tradutor: 0 artigo original utilizou a seguinte versão: SARTRE, Jean-Paul. 2007b. Nausea. Edited by Alexander Lloyd. New York: New Directions.
} 
túnel que ele, aparentemente, saiu? Ele corre na escuridão para se encontrar no mesmo lugar. Ele pode ouvir sua própria voz explicando que ele está em Red Creek Valley no mundo onde Ethan Carter desapareceu. A partir desses primeiros momentos do jogo, ele descobre que um mal desconhecido se reúne aqui. Há portais conectando diferentes mundos: um realista e sensível; e um segundo, misterioso e sombrio. Devido aos poderes paranormais do detetive, ele é capaz de reconstruir a ocorrência de eventos passados tocando em itens significativos encontrados nas florestas, casas e cemitérios. A fala interior do eu-avatar informa que "para encontrar Ethan, eu tive que descobrir o que este lugar está tentando esconder de mim" (THE ASTRONAUTS, 2014). Portanto, o jogo introduz a jogadora a uma facticidade diferente: uma nova facticidade no mundo em que os edifícios abandonados são habitados por forças das trevas e armas de assassinato, que, quando organizadas em locais apropriados, têm o poder de voltar no tempo e permitir à jogadora testemunhar cenas, em stop-motion, cruciais do crime.

Se fosse uma situação de vida, eu teria que tomar uma decisão livre sobre o que fazer, mas penso que uma situação de gameplay fornece uma fuga da necessidade de assumir a responsabilidade pelas ações e escolhas de um indivíduo. Para participar de uma situação de gameplay, eu preciso seguir pistas escondidas no mundo do jogo. Os significados já estão aqui. Como resultado, penso que os jogos de aventura poderiam satisfazer o anseio pela certeza, que é uma das necessidades humanas básicas do ponto de vista do existencialismo Sartriano. Em uma situação de gameplay,

\begin{abstract}
Cada uma das minhas escolhas, cada ato de direção intencional em relação ao mundo é moralmente e ontologicamente fundamentada, tem uma justificativa vital vinda de fora. Portanto, todos os relacionamentos (mundo-em-si, coisas-em-si), significados, valores e sentidos não são criados pela minha liberdade [...], mas são dados a mim como uma ordem já estabelecida. (MRÓZ, 2007, p. 783).
\end{abstract}

Foi assim que Piotr Mróz (2007) descreveu o espírito de seriedade, que apoia a crença de um indivíduo de que o sentido da vida pode ser derivado ou mesmo inscrito no mundo. Isso leva à conclusão de que regras e significados observados e experimentados no mundo, apenas por causa de sua presença, definem e justificam os esforços individuais. No espírito da seriedade,

0 homem busca o ser às cegas, ocultando de si mesmo o projeto livre que constitui esta busca; faz-se de tal modo que seja esperado pelas tarefas dispostas ao longo de seu caminho. Os objetos são exigências mudas, e ele nada mais é em si do que a obediência passiva a essas exigências. (SARTRE, 1997, p. 764). 
O significado das ações de um indivíduo é então percebido por esse indivíduo como dado pelas características do mundo - como sendo derivado diretamente da facticidade.

Numa situação de vida, segundo Sartre, o indivíduo e o mundo estão em polos opostos: são os dois tipos de seres tão diferentes quanto possível. A consciência, ou a liberdade humana, se esforça para esconder este fato. Para se sentir mais segura, ela tenta humanizar o mundo, para torná-lo compreensível e significativo. É por isso que tudo aquilo que é dado, como o conjunto de significados sociais e culturais, são geralmente percebidos como "coisas naturais" (SARTRE, 1997).

Penso que uma situação de gameplay não constitui tais pólos: não há nada de absurdo e não há liberdade, pois, esses aspectos ficam escondidos por trás do escopo da situação de gameplay. 0 momento em que tomo a decisão de ligar o jogo torna-se o momento em que entro na facticidade do eu-avatar no mundo do jogo7. Cada jogador se encontrará nessa facticidade e sua situação será determinada por ela. Os jogadores vão descobrir que o conjunto de significados internos do jogo não tem relação com suas liberdades individuais, mas sim com seu eu-avatar. Enquanto o eu-avatar estiver inextricavelmente ligado às estruturas experienciais de má-fé e espírito de seriedade, ele existe como um projeto realizado dentro da situação de gameplay. Portanto, o jogo não é simplesmente experimentado como o eu-mesmo da jogadora, mas como uma entidade emergente. Em consequência, como o eu-avatar é definido por seu posicionamento dentro do mundo do jogo, a liberdade da jogadora não pode simplesmente ser transferida para seu novo posicionamento.

O eu-avatar, assim como um ser humano no espírito de seriedade; "é esperado pelas tarefas dispostas ao longo de seu caminho." (SARTRE, 1997, p. 764). No entanto, existe uma diferença importante entre os dois; um indivíduo livre se autoengana de que não é ele o autor dos significados atribuídos ao mundo, enquanto o eu-avatar compreende reflexivamente que o significado do mundo do jogo é uma parte de seu projeto dentro dele sua forma estética. $\mathrm{O}$ mundo do jogo sustenta um senso de significado e propósito às ações que a jogadora toma ao confirmar e recompensar o desempenho apropriado. Além disso, dá suporte para a conviç̧ão de que os obstáculos oferecidos por um mundo do jogo são

${ }^{7}$ Sobre a noção de uma facticidade estendida, veja: Leino 2010. 
“exigências mudas" (SARTRE, 1997, p. 764) concebidas para espelhar as habilidades do euavatar'. E de fato, eles são.

Nesse ponto, eu gostaria de referenciar a suposição de Olli T. Leino de que os jogos exercitam a liberdade existencial da jogadora9 ao impor à ela a "condição de gameplay" (LEINO 2009; LEINO 2010; LEINO 2012b), a qual é definida a seguir como:

\begin{abstract}
A condição da jogadora, aquela que pela definição deseja jogar, é caracterizada por uma dualidade de liberdade e de responsabilidade: o jogo dá a ela a liberdade de escolha enquanto, simultaneamente, a torna responsável por essa liberdade ao resistir o projeto dela de jogar. (LEINO, 2012a).
\end{abstract}

Acredito que os jogos abrem novas áreas para a jogadora exercer a liberdade, mas somente quando são considerados da perspectiva externa; ou seja, quando a posição subjetiva dentro do mundo do jogo é agrupada. Do ponto de vista interno ao mundo do jogo, os jogos criam obstáculos também. Entretanto, não o tipo de obstáculos contra os quais minha própria liberdade pode ser exercida (ver LEINO, 2010). Seria o caso se o mundo do jogo fosse um mundo absurdo, onde os esforços humanos são injustificados. No entanto, quando abordado do ponto de vista do jogo da situação de gameplay e subsequente reflexão sobre ele, o mundo do jogo oferece ao ser humano um posicionamento diferente. Como ser humano, nunca deixo de ser livre; embora, ao agir como um eu-avatar, eu rejeite minha liberdade existencial de agir dentro da situação delineada pelo mundo do jogo. A situação do jogo cria uma oportunidade para esconder a liberdade da jogadora, pois estabelece o limite para a produção de significado dela mesma. Esta é a consequência do núcleo da situação de gameplay, onde o mundo do jogo absurdo não está oculto sob o espírito de seriedade da jogadora: não há mundo absurdo e indiferente no jogo.

O mundo do jogo, percebido a partir da perspectiva da situação de gameplay, não é absurdo, mas proposital. Seu significado é experimentado como inscrito nele; portanto, pode ser percebido como factual enquanto se adota a posição do eu-avatar. Mesmo que o significado experimentado em um momento específico seja limitado a algum tipo de expectativa ou atmosfera, todo o mundo do jogo existe para criar essa ambientação. Do ponto de vista da situação estética, o espírito de seriedade é, reflexivamente, descoberto

\footnotetext{
${ }^{8}$ Sobre a noção de intencionalidade híbrida, na qual "a intencionalidade híbrida originada na simbiose do artefato de jogo e o jogador é direcionada à facticidade ampliada" Leino 2010, 187, 277; Veja também: Vella 2014.

${ }^{9}$ A liberdade é aqui entendida de maneira diferente de, por exemplo, em Caillois já que não é tão ligada à ação, mas com a realização do projeto existencial dentro de determinadas circunstâncias, Caillois 1990.
} 
como parte da estrutura experiencial do eu-avatar, que é uma forma estética de seu posicionamento dentro do mundo do jogo.

Ao jogar $V o E C$, todos os itens interativos contribuem efetivamente para o significado do mundo do jogo. 0 eu-avatar segue caminhos que o levam a lugares que ele deve visitar para reconstruir o desenrolar dos eventos; para relembrar memórias de eventos passados escondidos no mundo do jogo. Não há becos sem saída, mas também não há dicas. 0 jogo avisa a jogadora no início: "O jogo é uma experiência narrativa que não segura a sua mão" (THE ASTRONAUTS, 2014); mas até mesmo uma folha de papel sobre a mesa da casa abandonada, cheia de rabiscos infantis, conta uma pequena história que ilustra o mistério que a jogadora tenta entender. Neste mundo de jogo, o eu-avatar pode ter certeza de que cada pedaço de jornal semi-queimado encontrado na floresta contém informações cruciais para sua missão ou contribui para o significado do mundo do jogo. A tarefa real do eu-avatar é encontrar o caminho para todos os lugares significativos e organizar todos os elementos na ordem correta. Cartas e vozes, feitiços e portais misteriosos constroem a totalidade lógica e narrativamente consistente em torno do eu-avatar.

Além disso, VoEC também faz uso de vários modos inovadores para auxiliar meu espírito de seriedade. Em vez de ser informado sobre as ações que devo realizar para atender às expectativas do mundo do jogo, sou guiado por sugestões que aparecem no mundo como questões em forma de nuvens de tags. Enquanto me aproximo de qualquer objeto importante, posso escolher investigá-lo. Por exemplo, ao me aproximar de um vagão de trem, consigo ver perguntas - "Sangue ... Humano? Animal? Assassinato? Usado recentemente?" (THE ASTRONAUTS, 2014); A representação deixa a impressão de que as perguntas que o detetive deveria fazer a si mesmo já estavam presentes no mundo do jogo, aguardando-o escondidas no objeto investigado. Portanto, elas não se referem a uma história que aconteceu no passado, mas à posição atual do eu-avatar em relação a este objeto e aos sinais do crime que a jogadora pode perceber. Quando olho em volta, a nuvem de perguntas está ficando mais densa à medida que me aproximo do ponto significativo em que encontrarei uma resposta. No entanto, quando olho na direção errada, a nuvem de perguntas se espalha. 
Figura 1 - Comportamento da nuvem de perguntas em VoEC
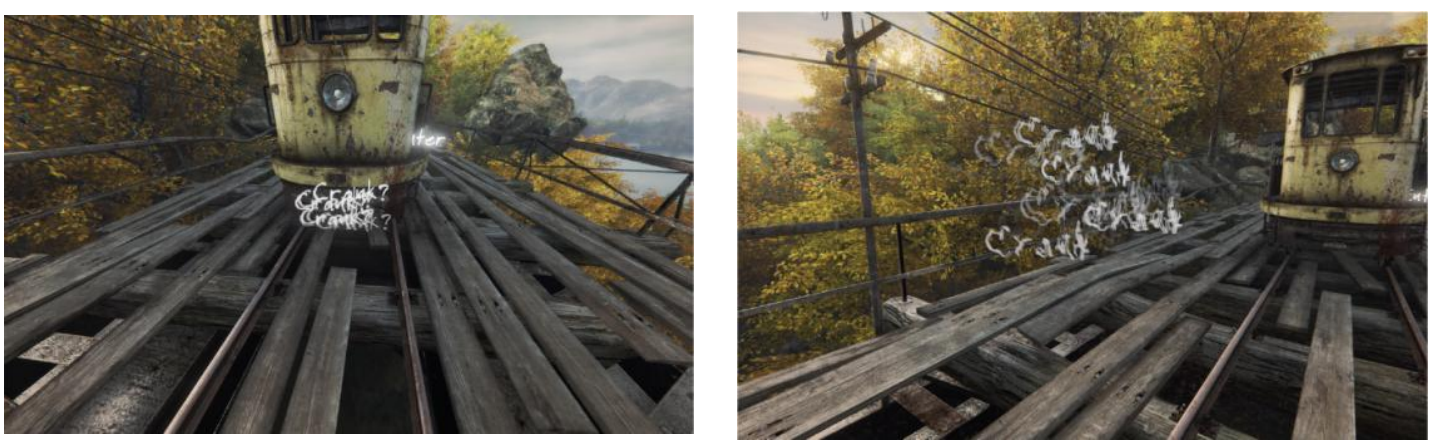

Fonte: A autora.

Por último, mas não menos importante, a faceta mais interessante do mundo de $V o E C$ são os flashbacks do passado. Quando eu consigo coletar e juntar todos os objetos necessários para reconstruir a cena do crime e "tocar" o corpo da vítima, o jogo me dá os momentos do crime em "stop-motion". Quando eu coloco os eventos na ordem correta, o dom especial do eu-avatar, que pode revelar significados misteriosos escondidos nos objetos dentro do mundo do jogo, me permite ver a cena com diálogos que revelam uma parte do mistério do desaparecimento de Ethan Carter.

A situação de gameplay, ao contrário de uma situação de vida, fornece uma explicação das ações que preciso tomar. Ela impõe um significado da situação na qual eu sou colocada como eu-avatar. Quem, então, é o ator dos esforços dentro do jogo, em quem esses significados são impostos e de quem são as ações justificadas?

\section{Eu, eu-avatar: agindo na má-fé}

\section{Assaltaram-me as recordações de uma vida que já não me pertencia, mas onde encontrara as mais pobres e as mais tenazes das minhas alegrias. (CAMUS, 1979, p. 277). ${ }^{10}$}

Na situação da vida, uma fonte de significado de um projeto existencial é sempre um ser humano. O significado individual é então executado "de dentro", mesmo que a justificativa das ações de uma pessoa seja atribuída erroneamente ao mundo. Na filosofia de Sartre, a necessidade de significado e destino pessoal nunca pode ser satisfeita sem ocultar a

\footnotetext{
${ }^{10}$ Nota do tradutor: 0 artigo original utilizou a seguinte versão: Camus, Albert.. 1988. The Stranger. Translated by Matthew Ward. New York: Vintage Books.
} 
liberdade. 0 ser humano no mundo está sempre em statu nascendi; devido ao seu status ontológico, ele nunca atinge a forma final e não pode apropriadamente atribuir a si mesmo um tipo de significado que os objetos não-humanos e os outros têm. Isso causa uma angústia; um sentimento de falta de fundamento que precisa ser ajudado.

\begin{abstract}
Esse desejo, de agir como um mecanismo motivado por causas externas, de tornarse apenas e somente uma única função, um traço, um papel, é uma das formas de má-fé, ou em outras palavras, um dos meios pelos quais o ser humano escapa de sua liberdade. (MITORAJ, 2005, p. 768).
\end{abstract}

0 termo má-fé designa aqui uma convicção de que alguém é determinado por e limitado a um papel desempenhado, e intencionalmente esquecendo que isso não é verdade. A má-fé é uma forma de autoidentificação falsa e poderosa de seres humanos livres; quando mentem para si mesmos sobre sua própria condição e são vítimas dessa mentira ao mesmo tempo (SARTRE, 1997). As pessoas que agem de má-fé são melhor ilustradas por personagens em Os Caminhos da Liberdade- A Idade da Razão, de Sartre: Brunet, que "tomara partido, renunciara à liberdade, era apenas um soldado" (SARTRE, 1963, p. 128) ${ }^{11}$; o barman que "era demasiado barman" (SARTRE, 1963, p. 184). Portanto, ocorre quando um humano passa a acreditar que ele é seu papel, um objeto ou mecanismo que não pode ser mudado ou modificado. "Talvez não possa ser de outro modo; talvez seja preciso escolher: não ser nada ou representar o que se é. Mas é terrível, essa trapaça da nossa própria natureza" (SARTRE, 1963, p. 184), pergunta-se Mathieu Delarue, obcecado pela liberdade.

Eu argumento que ao abordar uma situação de gameplay, a pessoa tem uma escolha; ou seja, não entrar em uma situação de gameplay em desdobramento, ou se autorrestringir e agir como um eu-avatar, ou seja, interpretar alguém que não é. Portanto, a má-fé pode ser explicada não apenas como uma descrição de uma percepção errônea da condição humana. Em uma situação de gameplay, a má-fé caracteriza a condição do eu-avatar como tal. Como resultado, é inevitável, desde que a jogadora queira participar da situação de gameplay. Quando a jogadora aceita a posição de eu-avatar como ela mesma, ela o percebe em uma "relação subjetiva de si mesmo" (VELLA, 2014), e é capaz de perceber de forma reflexiva a condição do eu-avatar. Desta forma, o ponto de vista do eu-avatar participando da situação de gameplay - isto é, seu posicionamento dentro do mundo do jogo - constitui uma base para a produção de significado em um jogo.

\footnotetext{
${ }^{11}$ Nota do tradutor: 0 artigo original utilizou a seguinte versão: SARTRE, Jean-Paul 1992. The Age of Reason: A Novel. Translated by Eric Sutton. Reissue edition. Vol. 1. Roads to Freedom. New York: Vintage.
} 
Neste momento surge uma pergunta: será que essa moldura existencial ainda pode ser chamada de "má-fé", se o eu-avatar, na verdade, não pode ser outra pessoa, já que não há lugar para liberdade e autenticidade dentro do mundo não-absurdo da forma como ele é abordado pelo eu-avatar ali situado? Eu acredito que sim, já que não é apenas uma questão de qualquer escolha particular feita dentro do mundo do jogo. A razão é uma construção do eu-avatar - uma composição do objeto e do sujeito, da forma estética e da existência - que está vinculada à forma proposta, uma vez que ele concretiza o mundo do jogo através de sua agência.

O eu-avatar não pode se tornar "mais ninguém"; no entanto, ele pode deixar de ser "ele mesmo". Além disso, isso acontece continuamente, à medida que a jogadora se mistura entre a posição interna e externa em relação ao mundo do jogo, o gameplay e a situação estética. $\mathrm{O}$ eu-avatar pode deixar seu posicionamento atual, o que a torna ela mesma em relação ao mundo do jogo, abandonando sua posição em relação ao mundo do jogo e terminando a situação de gameplay.

Além disso, a reflexão sobre o eu-avatar a partir do ponto de vista da situação estética não é apenas uma reflexão sobre o eu-mesmo, que assume a posição de avatar, assumida pela jogadora que se direciona ao jogo. 0 eu-avatar, desde que seja um composto do avatar e da existência, está em má-fé, pois ao atuar na situação de gameplay, a posição subjetiva toma limites e enquadra sua subjetividade. No entanto, devido à interação entre a situação de gameplay e a situação estética, ao refletir sobre sua posição de dentro do mundo do jogo, eles a abordam como a forma estética do eu-avatar. Por sua vez, quando o eu-avatar e a máfé dele são abordados a partir da perspectiva externa, a existência do jogador abandona seu posicionamento no jogo e se refere à sua liberdade, autenticidade e situação no mundo "real". No mundo do jogo não há lugar para nada fora das molduras delineadas para a existência através do eu-avatar. Ela preenche o desejo de ser eu-objeto: tornar-se-em-si-emsi-mesmo e suspender sua liberdade, o que não pode ser realizado na vida.

Portanto, a noção de má-fé fornece um enquadramento da situação de gameplay com as características de um ator. Enquanto a jogadora age como um eu-avatar, ela não experimenta um jogo como relacionado à liberdade dela mesma. Em consequência, o processo de produção de significado dentro do jogo não ocorre entre a facticidade e a liberdade do jogador dentro do jogo, mas refere-se ao papel objetivado do eu-avatar com o qual a jogadora se identifica. 
Um uso diferente do conceito Sartriano de má-fé foi proposto por Olli T. Leino (2010, 2012a). No entanto, Leino aplica a noção à uma situação externa ao mundo do jogo e constrói um experimento imaginário para representar um posicionamento específico da jogadora em relação ao artefato:

\begin{abstract}
Se eu fosse a jogadora relutante detida sob a mira de uma arma, excluindo a possibilidade de escolher não jogar, e começasse a jogar só porque 'não tinha outra opção', eu estaria envolvido no que Sartre [...] chama de má-fé. [...] Sob a mira de uma arma, a maioria de nós provavelmente recorrerá a qualquer modo de fuga disponível. Entretanto, fechar os olhos quando confrontados com um problema não seria uma boa escolha se nós [...] aceitássemos a autenticidade como um desafio comum aos humanos. (LEINO, 2010, p. 161-62).
\end{abstract}

Ele também propõe um outro lado para a má-fé, na qual ela não está conectada com a situação completamente independente do jogo em questão, mas se relaciona com o momento de cessar a atividade de jogar:

\begin{abstract}
Jogar, não diferente de qualquer outra atividade, pode ser terminada à vontade. No entanto, podemos e muitas vezes jogamos em má-fé - isto é, como se não tivéssemos a opção de parar. "Cheguei até aqui, não posso parar agora" ou "tenho que ajudar meus membros da guilda, não posso parar agora" ambos podem implicar uma atitude de má-fé. (LEINO, 2010, p. 162, nota de rodapé).
\end{abstract}

Os dois primeiros exemplos fornecidos por Leino descrevem condições independentes do posicionamento no mundo do jogo, enquanto o terceiro aborda a situação dentro do mundo do jogo como interpretada do ponto de vista externo. No entanto, nenhum deles se refere à situação do eu-avatar dentro do mundo de jogo no qual eu me concentro. Além disso, creio que a primeira citação se refere ao espírito de seriedade descrito acima e que a segunda contém dois casos diferentes. Portanto, vou exemplificar as diferenças entre as formas de má-fé em quatro sentenças:

O que Leino chama de "Jogadora relutante sob a mira de uma arma": "Eu jogo, porque sou forçado a jogar" - o significado da situação é atribuído ao estado do mundo, isto é, ser mantido à sob a mira de uma arma, e não à autopercepção de um indivíduo. "Eu" refere-se à jogadora e a restrição é externa e independente do mundo do jogo.

A jogadora [para Leino] que oculta que pode terminar o jogo à vontade:

a) "Eu tenho que jogar, mas já deveria ter terminado" - "eu" se refere à jogadora, e a sentença se refere à sua luta interior. No entanto, sua disposição para jogar e as limitações dela estão enraizadas na situação da vida; 
b) "Sinto-me obrigado a jogar por causa dos meus deveres no mundo do jogo" surge um conflito entre a jogadora e o eu-avatar, pois "eu" se refere à jogadora, enquanto "meus deveres" são os deveres do eu-avatar.

A perspectiva delineada aqui nesse presente texto - "Eu sou Paul Prospero, por isso tenho que encontrar Ethan Carter" -, uma limitação inscrita no eu-avatar. Como a restrição está dentro do mundo do jogo e não atinge a situação de vida do jogador, ela é inevitável enquanto durar a situação de gameplay. Mesmo que o jogador não esteja particularmente interessado em procurar pelo garoto, todas as decisões tomadas no mundo do jogo estão situadas em direção a essa missão.

Resumindo, pode-se observar que o conceito de má-fé pode ser aplicado não apenas às situações destacadas por Leino, mas também - acompanhado pelo conceito de espírito de seriedade - à situação de gameplay dentro do jogo. Além disso, do ponto de vista interno ao jogo, não há como fugir desses conceitos, já que são características internas do eu-avatar.

Deixe-me usar um exemplo de VoEC. 0 que significa dizer que dentro do mundo do jogo eu estou em má-fé? Eu percebo o mundo do jogo a partir de uma perspectiva de primeira pessoa. No início da aventura, o eu-avatar é quase como uma carta branca - apenas um ponto de consciência. Durante o gameplay, eu desenvolvo uma compreensão de um euavatar também como um personagem e uma incorporação. Como eu-avatar, me encontro na floresta de um estranho lugar chamado Red Creek Valley.

Primeiramente, eu me torno ouvinte do meu monólogo interno, o qual delineia meu posicionamento e molda minha perspectiva ${ }^{12}$. A voz do narrador - isto é, meus pensamentos - cria um comentário sincrônico para a situação em que estou; desdobra meu posicionamento no jogo. Como um experiente detetive particular que investiga casos obscuros, o eu-avatar - Paul Prospero experimentado como eu-mesmo - é o detetive que resolveu muitos casos na fronteira do crime e do mistério. Eu atendo um telefonema de um menino desaparecido, Ethan. Eu tomo o papel que é proposto para mim. Até agora, em relação ao gameplay, eu serei - como o eu-avatar - apenas um detetive procurando por Ethan Carter, não importa o quão bem-sucedido eu seja em meus esforços.

Mesmo que eu pare de cumprir meus deveres dentro do mundo do jogo, o eu-avatar ainda será tratado como Paul Prospero. Vou manter meus poderes sobrenaturais de ver o passado guardado na memória dos objetos. Mesmo que eu não queira acompanhar o

12 Sobre o modelo da relação jogador-figura, incluindo o dualismo interno de uma figura de avatar, veja: Vella 2014. 
gameplay e prefira me concentrar na apreciação da estética do ambiente, eu o percebo como e através do eu-avatar. Não importa o quanto eu tente evitar portais que levem ao misterioso mundo paralelo, não posso deixar de vê-los como Paul Prospero faz.

No início do jogo, eu encontro uma armadilha que, do ponto de vista do eu-avatar, parece ser feita especialmente para o visitante curioso sobre os mistérios desse lugar. Eu tomo mais cuidado e começo a procurar os próximos perigos escondidos entre as árvores. Depois de um tempo, encontro uma fogueira apagada. Como detetive, noto imediatamente um pedaço de papel que me fornece um fragmento de informação sobre o crime que estou rastreando. Se o eu-avatar fosse um guarda-florestal, não um detetive, ele provavelmente pensaria em caçadores furtivos tentando capturar um animal grande ao encontrar uma armadilha. Ela iria verificar se a fogueira está realmente apagada e se não representa algum risco de incêndio, e talvez tentasse localizar as pessoas que a acederam para multá-las.

Figura 2 - Objetos encontrados no início de VoEC
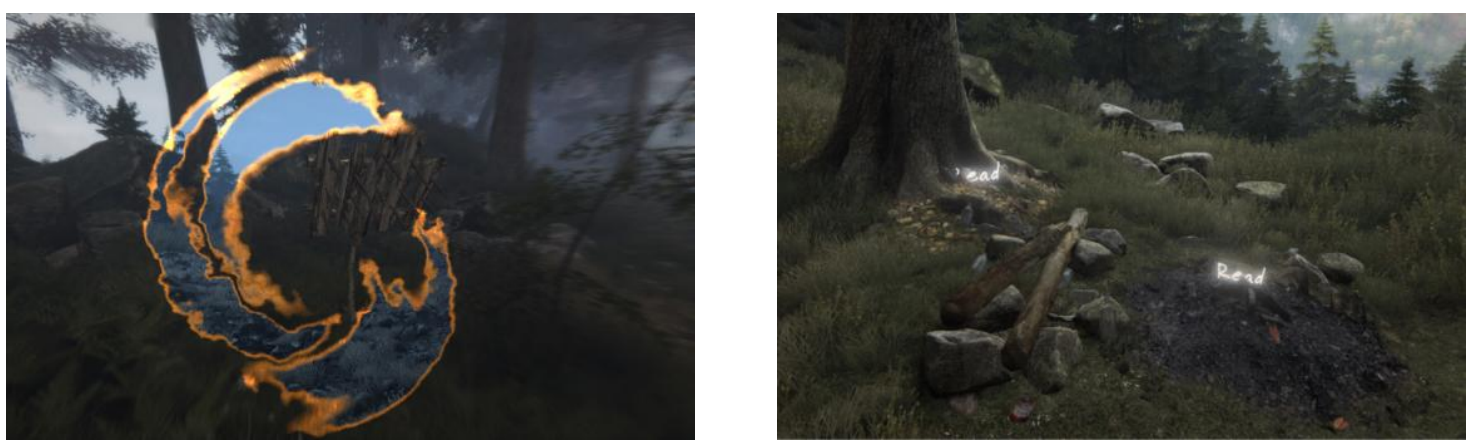

Fonte: A autora.

Portanto, o eu-avatar me fornece uma pré-condição existencial para entender minha situação no mundo do jogo. Má-fé constitui sua forma e me faz manter e desenvolver uma compreensão da minha própria posição. Ao coletar informações sobre o eu-avatar e aprender a agir dentro dele, gradualmente percebo que não há outra postura subjetiva proposta para mim dentro do mundo do jogo.

A importância da má-fé também pode ser ilustrada ao contrastar duas pessoas entrando em um café lotado. 0 detetive vai escolher um assento que lhe permitirá lançar um olhar furtivo ao suspeito que ele está seguindo, enquanto o barman notará o conteúdo dos copos que os clientes seguram. O barman do exemplo Sartriano, que é "demasiado barman" (SARTRE, 1963, p. 184), faz de cada gesto um gesto de barman, referindo-se a sua convicção 
de si mesmo como barman. Seu comportamento é liderado por sua má-fé, sua adequação é definida pela facticidade de ser um barman. Analogamente, a jogadora que pensa em si mesma como um eu-avatar e age como tal está olhando para o mundo de má-fé; procurando o que "apenas um detetive" procuraria. Portanto, em uma situação de gameplay, minhas ações são realizadas no contexto de uma missão que executo; isto é, em um contexto de sua relevância para o projeto do eu-avatar, minha aventura e do destino.

Em uma situação de vida, o significado do gesto de um barman é falsificado por sua má-fé. Ele pode a qualquer momento obter a consciência de que ele é um ser humano livre. Ele pode potencialmente deixar seu emprego, deixar de ligar o significado de suas ações ao seu papel e continuar vivendo sua vida.

Em oposição à vida, assumir este projeto particular do eu-avatar é justificado pelo mundo do jogo que é composto em torno de sua facticidade. Quando uma jogadora entra em uma situação de gameplay, seu eu-avatar sempre aparece no mundo do jogo em um momento perfeito e em um lugar ideal. Ela continua desempenhando um papel central no mundo do jogo13, à medida que o gameplay se torna um cumprimento desse projeto em particular, e sua mudança de facticidade sustenta continuamente sua justificativa.

Para experimentar uma aventura, eu ajo de má-fé como um eu-avatar. Eu atuo no espírito de seriedade enquanto procuro justificar meus atos no mundo do jogo. Portanto, em uma situação de gameplay em jogos de aventura, "Eu não estou 'me fazendo' contra o artefato como ele existe, mas assumindo que há um 'plano para minha existência'" (LEINO, 2012a). Leino chama essa abordagem de "modo utilitário de interpretação": "Embora a atitude utilitária inautêntica certamente seja útil para mim como um jogador, ela distorce minha interpretação, pois ela na verdade implica em uma versão da "falácia da intenção autoral" (LEINO, 2012a).

Enquanto considero uma experiência de uma situação de gameplay, eu não interpreto o jogo como um artefato, mas como um mundo que se espera que seja significativo. No entanto, não acho que isso exija mais suposições sobre as intenções de um designer; elas podem ser expressadas apenas no mundo do jogo com o qual a jogadora interage, desde que ela mantenha a posição dentro do mundo do jogo. Além disso, embora a distorção da minha interpretação possa ser prejudicial para a pesquisa de um artefato, parece ser crucial não

\footnotetext{
${ }^{13}$ Sobre o papel central do jogador nos cibertextos, ver Aarseth (1997); para o comentário filosófico sobre o papel central de um jogador em um mundo de jogo na forma de um jogo, veja Gualeni (2013).
} 
apenas para jogar um jogo, mas também para descrever a posição perceptual da jogadoraavatar dentro do mundo do jogo e para examinar uma situação de gameplay.

Quando a jogadora sai da posição de má-fé, a situação de gameplay é perturbada. 0 avatar não é mais percebido como a jogadora que salta de seu avatar e assume uma atitude diferente em relação a um jogo: ela o percebe como um artefato, não como um mundo. Ela a partir de então aborda uma situação diferente. 0 jogo não é experimentado como um campo de vida e de atuação, e se torna um artefato percebido de uma perspectiva externa. A aventura desaparece e é reduzida a uma história simples; algo que aconteceu uma vez e existe como já foi dito, a memória inacessível (SARTRE, 2000). Portanto, a proposta de aplicação da ontologia Sartriana limita-se a uma situação de gameplay, quando o jogador se objetiva no avatar agindo de má-fé, percebendo-se como "apenas um avatar". Desde que eu perceba o desenrolar do gameplay como minha própria aventura, meu olhar se funde com o olhar e a agência do meu avatar; eu posso agir como o avatar e pensar em mim como o avatar. A situação de gameplay permanece como uma experiência pessoal do significado diferente da vida no jogo - o diferente eu-mesmo na facticidade estendida.

\section{Sobre a apropriação do mundo de jogo e o projeto do Avatar}

Em uma situação de vida, os seres humanos são capazes de rejeitar a má-fé e o espírito de seriedade e autenticamente assumir a responsabilidade por sua liberdade. Por outro lado, em uma situação de gameplay de jogo de aventura, eles não são; contanto que a má-fé e o espírito de seriedade forneçam uma moldura perceptiva para a jogadora, e que ele sempre siga o gameplay. 0 significado da vida no jogo é experimentado na má-fé quando a jogadora age como um eu-avatar; e em espírito de seriedade, de forma que ela perceba o significado como sendo dado a ambos. Portanto, em uma situação de gameplay, a jogadora é capaz de experimentar a suspensão da liberdade e se deliciar com a falta de responsabilidade. Quando eu assumo a posição do eu-avatar em má-fé, o mundo do jogo se torna significativo para mim à luz do projeto do meu avatar. A facticidade deste mundo e a adequação do projeto do avatar faz com que o mundo seja experimentado no espírito de seriedade como sendo significativo, satisfazendo expectativas e justificando meus esforços. 


\section{Referências}

AARSETH, Espen. Cybertext: Perspectives on Ergodic Literature. [s.l]: The Johns Hopkins University Press, 1997.

AARSETH, Espen. I Fought the Law: Transgressive Play and the Implied Player. In: DIGRA, 2007, [s.l]. Proceedings[...]. [2007. p. 130 - 133.

CAILLOIS, Roger. Os jogos e os homens: a máscara e a vertigem. Lisboa: edições Cotovia, 1990.

CAMUS, Albert. O Estrangeiro. Tradução Antonio Quadros. In: CIVITA, Victor (Ed.). Estado de Sítio; O Estrangeiro. Traduções de Maria Jacintha e Antonio Quadros. São Paulo: Abril Cultural, 1979. P.300.

CAMUS, Albert. The Stranger. Tradução de Matthew Ward. New York: Vintage Books, 1988.

DILMAN, Ilham. Free Will: An Historical and Philosophical Introduction. New York London: Routledge, 2013.

GUALENI, Stefano. Necessary Evil. 2013. Disponível em: http://evil.gua-le-ni.com/. Acesso em: 02 abr. 2019.

LEINO, Olli Tapio. Understanding Games as Played: Sketch for a First-Person Perspective for Computer Game Analysis'. In: THE PHILOSOPHY OF COMPUTER GAMES CONFERENCE, 2009, Oslo. Proceedings [...]. Oslo: 2009.

LEINO, Olli Tapio. Emotions in Play: On the constitution of emotion in solitary computer game play. 2010. Tese (Doutorado) - IT University Of Copenhagen, Copenhagen, 2010.

LEINO, Olli Tapio. Untangling Gameplay: An Account of Experience, Activity and Materiality Within Computer Game Play. In: SAGENG, John Richard et al (Ed.). The Philosophy of Computer Games. Dordrecht: Springer, 2012. p. 57-76.

LEINO, Olli Tapio. Death Loop as a Feature. The International Journal Of Computer Game Research, [s.l], v. 12, n. 2, 2012.

MITORAJ, Robert. Na drogach złej wiary. In: SARTRE, Jean-Paul. Drogi wolności. Kraków: Zielona Sowa, 2005. p. 765-773.

MRÓZ, Piotr. Posłowie. In: SARTRE, Jean-Paul. Byt I Nicość: Zarys Ontologii Fenomenologicznej. Kraków: Zielona Sowa, 2007. p. 771-788.

SARTRE, Jean-Paul. Os Caminhos da Liberdade: a idade da razão. v. 1. ed. 3 Tradução de Sérgio Milliet. São Paulo: Difusão Européia do Livro, 1963.

SARTRE, Jean-Paul. Os Caminhos da Liberdade: com a morte na alma. v. 3. ed. 4. São Paulo: Difusão Européia do Livro, 1968. 
SARTRE, Jean-Paul. 0 Ser e 0 Nada: ensaio de ontologia fenomenológica. 2 ed.. Petropólis: Vozes, 1997.

SARTRE, Jean-Paul. A Náusea. 10. ed. Rio de Janeiro: Nova Fronteira, 2000. p. 259.

SARTRE, Jean-Paul. Drogi wolności. Kraków: Zielona Sowa, 2005. Tradução de Julian Rogoziński.

VELLA, Daniel. "Who Am 'I' in the Game?": A Typology of the Modes of Ludic Subjectivity. In: DIGRA, 2016, [s.l]. Proceedings[...]. 2016.

VELLA, Daniel. Player and Figure: An Analysis of a Scene in Kentucky Route Zero. In: DIGRA, 2014, [s.l]. Proceedings [...]. 2014.

\title{
Referências Ludográficas
}

THE ASTRONAUTS. The Vanishing of Ethan Carter. PC, 2014.

\section{Spirit of Seriousness and Bad Faith}

\begin{abstract}
This theoretical essay explores the players experience and situatedness within the game world from an internal perspective, seeking to understand the conditions of a gameplay situation as a "self-avatar". It analyzes the aspects of the gameworld, the player, and the avatar of The Vanishing of Ethan Carter to illustrate and to support its arguments about the meaning-making process forward the self-avatar in-game situatedness. It contextualizes existentialist concepts referring to life situation developed by Jean-Paul Sartre, such as bad faith and spirit of seriousness, in the gameplay situation, reflecting theoretically on the in-game relationship between being, player, and avatar through the intersection of philosophy and games studies. It proposes that the production of meaning and players interpretation of their individual experience occur due to the interplay between multiple perspectives, opened by the complexity of the player's situatedness towards the game, the avatar, and the gameworld. It endorses that the player's perspective and situatedness within the gameworld cannot be experienced separately from the avatar, since the self-avatar is an emergent being situated within the gameworld consisting both of the player's existence and intentional acts, as well as the features of the avatar.
\end{abstract}




\section{Keywords:}

Avatar. Gameworld. Gameplay. Meaning-Making. The Vanishing of Ethan Carter. 